\title{
Suturing Working Class Subjectivities: Media Mobilizing Project and the Role of Media Building a Class-Based So- cial Movement
}

\author{
Peter N. Funke*, Chris Robe**, and Todd Wolfson*** 1 \\ * Department of Government and International Affairs, University of South Florida, Tampa, FL, \\ USA, pnfunke@usf.edu,http://gia.usf.edu/faculty/pfunke/ \\ ** School of Communication and Multimedia Studies, Florida Atlantic University, Boca Raton, FL, \\ USA, crobe@fau.edu, http://www.fau.edu/scms/robe.php \\ *** Department of Journalism and Media Studies, Rutgers University, New Brunswick, NJ, USA, \\ twolfson@rci.rutgers.edu, http://comminfo.rutgers.edu/directory/twolfson/index.html
}

\begin{abstract}
Due to the increasingly atomized, isolated nature of social life, as well as the apparent splintering of the working class under neoliberal capitalism, media serve a pivotal infrastructural function for generating the necessary commonality between the fractured sectors of the contemporary working class. This article ethnographically and textually examines how the media driven practices of the Philadelphia-based Media Mobilizing Project helps collectively suture fragmented groups of workers into a class formation that begins to resist and challenge the hegemony of neoliberal practices. As our detailed analysis of MMP's 2007 to 2009 montage reels show, MMP videos serve the primary purpose of fostering class alliances not only through their viewing, but also, and perhaps more importantly, through their making. As such, we do not consider media in general and the MMP videos in particular as an endpoint unto themselves, but instead as catalysts for further organization building and the renewed suturing of the multiple components of what we understand as a contemporary urban working class. Through a host of old and new media platforms (radio, video, web) MMP works with different segments of the neoliberal working class, such as immigrants, urban youth, and low-wage workers, to create a class identity at the local and regional level.
\end{abstract}

Keywords: Capitalism, Class Formation, Media, Social Movements, Suture

"From the beginning, we very deliberately were about creating a new identity through this process. The work of montage is important for this new possibility of subjectivities" (Shivaani Selvaraj, Media Mobilizing Project Co-founder).

\section{Introduction}

There is growing consensus across the social sciences that the last thirty years have borne witness to seismic shifts in the configuration of the global economic order. Characterized as a transformation from fordism to flexism (Harvey 1990), this new system is differentiated by the speed and mobility of capital, goods, people and ideas. The fluidity of both objects and ideas has led to varied forms of analysis-including rescaling notions of state power, remapping forms of sovereignty and reconfiguring modes of subjectivity. At the same time, there has been a significant lack of attention to the way these structural shifts have impacted the category of class as well as the intersections of class identity and new communication technologies.

In this article we investigate the role that media and communications play for the construction of contemporary class-based social movements. We ethnographically and textually examine the media driven practices of the Media Mobilizing Project (MMP). MMP is both an organization devoted to creating a community-based media infrastructure and it is a network of organizations across the Philadelphia region that aims to "build a movement to end poverty led by the poor and working class, united across color lines" (MMP 2010). The central tactic of MMP is to utilize media (radio, video, web) as the "nervous system" that conjoins and sutures people across the region into new class-based subjectivities.

MMP serves the two primary goals that John Downing identifies as comprising radical media: "a) to express opposition vertically from subordinate quarters directly at the power structure and against its behavior; b) to build support, solidarity, and networking laterally against policies or even against the very survival of the power structure" (Dowing 2001, xi). While MMP critiques reactionary aspects of commercial media's unsympathetic portraits of working-class concerns, the central aim of MMP is to foster solidarity among working-class people through media production that al-

\footnotetext{
${ }^{1}$ This article was written collaboratively by the three authors: there is no first author. The authors' names therefore appear in alphabetical order.
} 
lows them to share stories, to feel empowered to produce their own media and to collectively mobilize in an effort to build a larger movement.

In the following, we explore the ways in which media is used in generating class-based identities in an effort to reinsert and re-examine socio-economic class in an era of growing economic inequality. The widespread assumption is that we are living in a moment of broad social change (economic, technological, political, cultural) in which old forms of collective identity have disappeared. As such, concepts of class and class identity are considered a bygone logic of the industrial era, which has given way to more fluid, hybrid forms of collective identity revolving around more visible signifiers such as ethnicity and gender. While it is vital to understand these forms of collective identity, socio-economic class as a prism through which life is experienced has hardly vanished. We build on scholars that have argued for a new concept of class in the era of neoliberal capitalism (Hardt and Negri 2004, Wacquant 2007), and in this article we begin to theorize on the central role of media in re-forging a contemporary working class identity within this context.

After presenting our theoretical framework and introducing the concept of "media-suturing" as integral to an understanding of movement-based class formation, we introduce the Media Mobilizing Project (MMP) and its media practices. Following this we ethnographically and textually examine the ways in which MMP attempts to suture the different segments of the contemporary working class (i.e. immigrants, urban youth, low-wage workers) into a primarily class-based formation. As such, this article pays particular attention to MMP's organizational practices, their cultural mode of producing media, and the media texts themselves. As our detailed analysis of MMP's 2007 to 2009 montage reels show, MMP videos serve the primary purpose of fostering class alliances not only through their viewing, but also, and perhaps more importantly, through their making. As such, we do not consider media in general and the MMP videos in particular as an endpoint unto themselves, but instead as catalysts for further organization building and the renewed suturing of the multiple components of what we understand as a contemporary urban working class. Along these lines, both the media texts and production process of MMP bring to the fore, what we see as the elevated infrastructural dimension that media plays in class formation. As Nick Couldry asserts, "in considering possible sites of resistance to media power, we must look not only at the distribution of economic and organizational resources and at contests over specific media representations of reality, but also at the sites from which alternative general frames for understanding social reality are offered" (Couldry 2003, 41). Therefore, this essay emphasizes the physical spaces that assist MMP in producing a more coherent class-based identity.

Through this research we provide a particular example of how media practices are used by poor and working people to suture class identity. Within a host of old and new media platforms (radio, video, web) MMP works with different segments of the neoliberal working class, such as immigrants, urban youth, and low-wage workers, to create a class identity at the local and regional level. This is not to say that media-making alone allows for a unified class-based identity to form. Clearly, as we emphasize throughout the essay, collective action and protest, theoretical analysis and historical understanding, informal discussions and a central location remain important determinants for working-class movements to coalesce. But, within a highly fragmented and precarious neoliberal age, media-making serves as a central function in fostering and/or intersecting with the aforementioned activities. To gain analytic purchase of media-based movement building in general and MMP's media practices and videos in particular, we first discuss our concept of class in the age of neoliberal capitalism and then re-visit the cinematic concept of suture.

\section{Communication and Contemporary Class Formation}

In this article we make an argument for the fundamental role of communication generally, and new and old media tools specifically, for forging class identity in the age of neoliberal capitalism. This contention is based on a few specific insights about the intersection of capitalism, class and technology. The first point is that class-consciousness emerges out of a dialectical relationship between objective and subjective conditions. This was first argued by Karl Marx in The Poverty of Philosophy (1992), when he maintained that while class emerges within the context of objective socio-economic and political structures, it is through class struggle that a class becomes united and transforms from a class in itself to a class for itself.

Georg Lukacs (1972) and EP Thompson (1966) picked up on this current in Marx's thinking as they both argued for a dialectical approach to class formation. For instance, in Thompson's seminal study The Making of the English Working Class, he echoed Marx, arguing: "Classes arise because men and women, in determinative productive relations, identify their antagonistic interests, and come to struggle, to think and to value in class ways: thus the process of class formation is a process of self-making, although under conditions which are 'given"' (Thompson 1978, 106-107). 
Informed by these dialectical conceptions of class formation, in this essay we see classconsciousness as something that emerges through structured processes. By this we mean that while people's structurally determined objective conditions (here neoliberal capitalism) are key to creating a set of shared social circumstances (precarious working situations, over-stretched bank accounts, debt, dependence on underperforming public schools, etc.), it is through a set of collectivizing processes such as struggle and communication, that classes of people recognize these common conditions and, consequently, recognize their shared interest in change and their role as a historical agent.

The second insight that informs this article is that capitalism is a historical and dynamic phenomenon, changing over time and space. Across the last forty years, the deregulation, privatization and liberalization processes of capitalism (Harvey 1990 and 2005) have expanded and deepened the reach of a neoliberal logic, forging a global division of labor while penetrating into what were once public sectors of society such as education and health care. These shifts towards neoliberal capitalism or what autonomists call the "social factory" (Tronti 1966) or the "factory without walls" (Negri 1989) have had material outcomes, changing the nature of the urban United States working class from industrial workers to a broad new class of workers that include service sector workers, creative workers, the traditional industrial proletariat, students and the un and underemployed amongst others (Fuchs 2010). A further characteristic of this new working class is their political isolation and demobilization (Goode and Maskovsky 2002, Sites 2007). In this sense the neoliberal working class is thus both expanding as new parts of the population are coming under the capitalist profit logic, as well as fragmenting, as the this new class formation is more isolated than the industrial proletariat.

This transformation in the nature of the working class brings forth new questions regarding the process of class formation. We argue that given their atomized and isolated societal positioning, the neoliberal working class faces a more challenging prospect of generating relations than previous periods, and thus demand a different and arguably more complex process of constructing class identity. Along these lines the central problematic of this essay is to begin to outline some of the emergent dynamics among the various splintered sectors of the neoliberal working class, to discover what Hardt and Negri call "the common" in order to "communicate and act together" (Hard and Negri, 2004: xv) - to establish and maintain a class identity? In the rest of the article we argue that communication emerges as one critical vehicle through which class formation takes place in contemporary society. Moreover, as we argue elsewhere (authors, forthcoming) communication plays an elevated role in contemporary class formation because of the isolated fragmented nature of the working class.

\section{The Socialized Suture: Rewriting a Cinematic Concept}

Suture theory emerged as one of film studies' central theoretical concepts throughout the 1970s as it incorporated elements of French post-structuralism into its framework. Although this general theoretical turn yielded many methodological and conceptual insights, it nonetheless disparaged the study of documentary and activist cinema as a hopelessly naîve endeavor that bolstered the supposedly uncritical acceptance of cinematic "realism" that such filmmaking endorsed. This reductive conceptualization of "realism" led to dire consequences for the discipline, delaying any sustained development of documentary film theory until the late 1980s and jettisoning most analysis of media activism to communication studies.

We, however, would like to redeploy suture in a more collective and materialist direction that can bridge the divide between the formalist concerns of 1970s film theory and the media-making practices of a contemporary movement building coalition, the Media Mobilizing Project (MMP). Although the debates concerning suture remain far too complex to address here, we want to quickly stress its origins within cinema studies. Based off of Jacques-Alain Miller's development of the Lacanian concept, English-speaking film theorists like Kaja Silverman, Stephen Heath, Laura Mulvey, and Collin MacCabe appropriated it to provide ideological analysis of narrative cinema. As Stephen Heath explains, "Ideological representation depends on [suture] [...] this 'initial' production of the subject in the symbolic [...]" (Heath 1981, 14). More importantly, "the cinematographic apparatus itself is nothing but an operation of suture." (Heath 1981, 14)

Hundreds of articles soon followed concerning the ways in which narrative cinematic conventions either successfully and/or unsuccessfully sutured viewing subjects into the ruling ideology. Most analysis remained decidedly formal, focused determinedly on the cinematic object while remaining trenchantly indifferent to production, distribution, reception, and consumption practices. Even within these limits, cinema studies honed its close-analysis of cinematic forms while theorizing the complex modes of psychic identification that course through popular culture and cannot be 
simply reduced to "duping the public," the somewhat knee-jerk and psychically-simplistic concept that too many communication scholars invoke. Recognizing it's Althusserian inflected value in accounting for the complex psychic drives that interpellate individual subjects into ideology, we extend the concept of suture in more socialized and materialist directions by looking at how suturing operates across a community instead of focusing solely on the role of suturing in interpellating a singular subject. In this sense we redefine the concept of suture through analyzing the ways in which the Media Mobilizing Project utilizes video production to assist in collectively suturing fragmented groups of workers into a unified class formation that can begin to resist and challenge the hegemony of neo-liberalism. Our goal is not unlike Michael Renov's own desire to re-define suture in more collective directions when analyzing Newsreel films of the 1960s and early 1970s. Renov claims that the 1960s asserted a "new subjectivity [that] was most dramatically shaped and galvanized by the visual regime most conducive to the complex plays of projection, introjections, and identification-that is, cinema"(Renov 2004, 10). The proliferation of underground art and youth culture gestured towards "a culturewide effect of suture by discursive strategies such as the use of the first person plural, the recovery of certain avatars of revolutionary struggle by an act of joyful historical revisionism, or by an emphatic reiteration of shared gesture or bodily linkage-the embrace of arms, the raised fist of solidarity" (Renov 2004, 15).

Although the present cannot be conflated with the 1960s, we would like to argue that the global justice movements of the 1990s and 2000s in response to the hegemony of neoliberalism have also produced a new subjectivity. The Media Mobilizing Project represents both an outgrowth of this new subjectivity, as well as a revision of it. As a result, we want to investigate the ways in which the Media Mobilizing Project both locally and globally, both formally and materially attempts to suture this new subjectivity into a primarily class-based formation.

The symbolic importance of the ways in which media production alters people's everyday lives has been well-documented by Clemencia Rodriguez. She notes how citizen's media allows for "opening social spaces for dialogue and participation, breaking individuals' isolation, encouraging creativity and imagination, redefining shared social languages and symbols, and demystifying the mass media" (Rodriquez 2001, 63-64). This article develops upon this insight by investigating how the psychic mechanisms of suture provide for such collective transformations to occur. As Michael Renov notes, "The notion of desire developed in psychoanalytic theory is a crucial and generally neglected component of documentary spectatorship that deserves our careful consideration." (Renov 2004, 96) MMP provides a concrete example of the ways in which one contemporary organization's digital video production fosters collective identification through production and exhibition practices, as well as formally.

\section{MMP and Media-Making}

Generally speaking, the Media Mobilizing Project has been influenced most directly by the poor people's organizing that stretches back to the 1960s and the Indymedia movement of the 2000s and to a lesser degree the Media and Democracy movement, which developed in the 2000s. Existing at the nexus of independent media making and antipoverty organizing, MMP builds and goes beyond these traditions. Through sharing technological skills with disadvantaged groups, using media production, screening, and analysis to draw together diverse working-class organizations, and presenting the stories of the working poor that commercial media regularly neglected, MMP seeks to use media to conjoin the often isolated groups and their struggles. Furthermore, it attempts to make all aspects of media production available to people who lack professional training and the necessary time and money to engage in commercial media-making. MMP, in other words, challenges the traditional mode of media production. As a result, as Chris Alton observes, it is this type of media-work "with respect to the relations of production that gives it its power and enables it avoid recuperation by the mere duplication of its ideas" (Atton 2002, 18).

MMP's primary mission is thus to foster collective organizing both within singular groups, like taxi drivers, hotel workers or high school students, and across them in an effort to build a larger shared movement. The crafting of stories and suturing of collective working-class identities through video, audio, and written word serves as a central vehicle in such organizing. On the basis of the increasingly isolating and alienating nature of work under neoliberal capitalism in general and in the service sector in particular, MMP provides a venue that can help re-connect these workers with one another, a point which converges with other research on service sector workers (Liu 2004). Ronald Blount, a member of MMP and president of the Philadelphia-based Taxi Workers Alliance, observes the positive impact that media-making has had in countering the alienating work of cab driving: "It is one of the most isolated occupations you can do. You are competing against other drivers for fare money. You are in a cab 16 hours a day. This media-making has started to break-down 
these barriers. Cab drivers are starting to see themselves as a class instead of as individuals struggling against each other" (Blount 2010). This coincides with MMP's mission as articulated by Rebekah Scotland, who works as MMP's lead video organizer: "One individual working on something doesn't draw him or her closer to the work that we are doing. It is about the collective experience of organizing the work. The people who are involved with it are coming from different backgrounds, coming across various sectors. As a result, we get a sense of where other people are coming from, a sense of other perspectives" (Scotland 2010).

As Ronald Blount and Rebekah Scotland exemplify, MMP seeks to suture new collective subjectivities and class formations in relation to the material realities of its constituencies. Using media to relate and converge the atomized sectors of the neoliberal working class, MMP seeks to construct class identity through various media practices. Elsewhere (Funke and Wolfson, forthcoming) we have called this approach a model of concentric practices. These concentric practices provide us with a conceptual framework of how contemporary class formation occurs through the use of media and communications in a neoliberalizing city such as Philadelphia. We see this complex of interrelated dynamics as illustrative of the process of thickening and converging that occurs across the atomized and fractured contemporary working class through media and communication. More specifically, MMP's concentric practices can heuristically be analyzed along three overlapping practices, which aim to suture a "common" among the different fragments of the working class: communicative spaces, narrative practices and shared struggles. Simply and somewhat schematically put, communicative spaces lay the groundwork for bringing people together in the "same room," for starting to share experiences, for providing the necessary knowledge of the technical tools of our time as well as for generating the necessary analytic skills. Narrative practices then "channel" the beginnings of communality as well as the skills built through communicative spaces, framing and directing them to then lead into shared struggles based on the realization of a shared class identity.' Put differently, shared class identity and struggles develop through a chain of media sutured and interlinked concentric practices, from generating trust and certain understanding of commonality at face-to-face encounters, to analyzing mass media's bias and creating alternatives messages to mobilizing and organizing in shared struggles. These three suturing dimensions we conceptualize as concentric practices with one inside the other. As a heuristic device, the communicative spaces would then describe the shared center, a necessary part for the narrative practices. Both the communicative spaces and narrative practices would then be necessary (but not sufficient) to constitute and generate the third practice of shared struggles. Put differently, shared MMP struggles need common narrative practices, and both rely on communicative spaces, describing a concentric relationship between the three practices.

After illustrating suturing processes in the aforementioned Communicative Spaces we will focus specifically on Narrative Practices. As the then following textual analysis of MMP's media making shows, Narrative Practices necessarily overlap with the Communicative Spaces and Shared Struggles in the formation of class identity. Narrative practices such as MMP's video reels are thus not merely endpoints in themselves, but catalysts for further organization building and sustained processes of class formation.

\section{Communicative Spaces}

Providing what we call communicative spaces, where various fragmented groups of the workforce can simply meet and exchange stories, remains an important facet in initiating class solidarity. At communicative spaces, which are the face-to-face trainings, media screenings, community dinners and other collective moments, people are brought together in an effort to "build community." Rebekah notes, "We need to start with a space where there is conversation and discussion so people can provide their stories. Most of our conversations are not about the technical side of filmmaking, but about the story and what and who we are trying to connect with. Then we are all learning in the process" (Scotland 2010). Thomas Robinson, president of the Philadelphia Security Officer's Union (PSOU), marks the profound impact a collective space had upon his thinking: "At first, we were submerged in our own struggles and our own issues. We didn't realize so many other sectors of the workforce were going through what we did. Not until you have these spaces and draw these groups together. It is almost like they are speaking directly to you. They don't know you. I don't know them, yet they have the same feelings that you are feeling, the same thoughts that you are having. You are no longer alone in these types of situations" (Robinson 2010).

This physical space provides a main location where the suturing of identity across the fragmented sectors of the working-class begins and is sustained since organizing, studying, outreach, and media-production all converge there. As Ronald Blount succinctly summarizes: "There is always a mixture of study, media-making, and outreaching with other people." Media-making be- 
comes intimately linked to collective discussion. Adding to Ron's summary, Bryan Mercer, MMP's Digital Inclusion Organizer insists that filmmaking "is both conceiving how the story should be structured, which is done collectively through meetings, and the physical editing it together" (Mercer 2010). The conceptualizing of the story, which leads to cross-identification between workers, is seen as a core aspect of media-making.

This emphasis on space becomes an important reminder that one must always remain aware of how shifting and developing organizational practices and structures affect the types of media produced. Film historian David James (1996) explains how "every work of art expresses the social uses it serves, and works that do not directly serve capital articulate in one way or another their position in respect to capitalist culture generally. All works thus contain within them the stories of the mode of their productions" (James 1996, 15) For MMP, the videos that we will be investigating serve the primary purpose of fostering class alliances not only through their viewing, but also, and perhaps more importantly, through the making of them. The videos and their production practices give voice to working-class hopes, desires, and frustrations in response to a neoliberal regime that seems at best indifferent to their needs, if not directly opposed to them-all the while attempting to interweave these multiple insights into unified class alliance and narrative that can yield further collective action. As film scholar Faye Ginsburg observes, alternative media productions not only create innovative works and critical frameworks, but also produce new "social relations [...] through practice, that can change the ways we understand media and its relationships to the circulation of culture and more generally in the twenty-first century" (Ginsburg 2008, 303-304). As a result, we must not present the videos as an endpoint unto themselves, but instead as catalysts for further organization building and the renewed suturing of class alliances.

Not surprisingly, then, another central component of media-making is skills-sharing, which usually takes the form of classes held once or twice a week over a few month period. Although learning the equipment occupies a certain amount of time, media literacy proves a crucial element for working-class students. Thomas candidly observes, "I was very ignorant of how mainstream media portrays most stories. I didn't understand the need for independent media. I was one of those people who read a newspaper every single day. I thought I was informed. But you realize that I wasn't as informed as I thought so" (Robinson 2010). Ronald Blount adds, "I didn't understand the importance of one word having a meaning, a certain phrase having a meaning [...] For example, sometimes the commercial press would do a story on us. Personally, the story sounds okay. But then we would meet collectively and start looking at it and realize, 'they are sending a negative message about us" (Blount 2010).

Completing their own films, as Thomas did in creating a seven-minute documentary on flashmobs in Philadelphia, or collective films, as Ronald did concerning the Taxi Workers, leads to a newly found pride, confidence, and ultimately power. First of all, the members discover their own voice. As Thomas asserted, "Four or five years ago, I wouldn't be able to speak to you on the phone. I would be afraid of who I am talking to, who is going to read the publication. I would be worried about the backlash. I am a different person. I have the strength and courage to tell our story over and over again. We know we are right in doing it" (Robinson 2010). In turn, the MMP facilitated processes led the groups involved to gain more power through greater clarity and a shared sense of mission, ultimately forcing power structures to listen and respond. Ronald Blount asserts that the Taxi Workers can now get things done with just a phone call rather than a protest: "We can just make a phone call if someone is harassing us at the airport, and then it stops. Or if parking authority places tickets on our windows without being visible, it can just stop. Last week we went to the independent regulatory review commission to see what is good and what is legal. Five years ago they would have said, 'You have to follow these guidelines and that's that.' Now they gave us a power-point presentation and addressed us personally. It has taken our organization to a new level" (Robinson 2010).

The videos produced by MMP members serve multiple purposes. Some, like the Taxi Workers videos, are geared towards gaining public support for their causes. Alternatively, the early videos by and about the Philadelphia security officers were aimed at helping them build their membership, as part of a drive towards unionization. The Head Start video Hope in Hard Times, on the other hand, was made while the national Head Start program was being reviewed for federal funding. The video was aimed at showing the importance of local Head Starts in their communities as well as the important leadership of people living in poverty in directing Head Starts through policy councils. This video then was targeted towards members of the US Congress with Pennsylvania Head Start burning 600 copies and making sure every member of the US Senate and Congress received a copy prior to the vote for refunding the national Head Start program. But what all the videos and their production practices reveal is how growing collective power accompanies a sense of personal 
growth and empowerment. Psychic transformation, in other words, is an integral part of developing collective action, emphasizing the need for a psychoanalytic understanding of such processes, which suture theory in part provides.

\section{Narrative Practices}

For the remainder of this essay, we want to focus on MMP Narrative Practices. Narrative Practices describe the processes of "channeling" the beginnings of communality as well as the skills built through communicative spaces, to produce a common understanding of struggle and class identity. As such, MMP media makers aim to craft messages that place different segments of the fragmented working class in a shared frame, to illustrate commonalities between these splintered and atomized sectors and to ultimately generate a class based identity. As such, MMP media texts seek to link, for instance, first generation Haitian cab drivers, to African-American urban youth and working class white nurses. In the following section we focus on the 2007, 2008, and 2009 end-ofthe-year montage reels that MMP produced for its membership dinner held every December, which brings together roughly 150 lead organizers and movement builders from MMP's constitutive groups and movements. We do this for two primary reasons: First, the clip reels dramatically reveal the changes in aesthetic form and focus that accompany MMP's organizational growth. They expose the traces of MMP's ever-developing organizational structure in both their assembly and the overall quality of the videos that they incorporate. Furthermore, they strikingly encapsulate the commonalities that unite the yearly productions, as well as expose the aesthetic developments and changes in perspective between years, which the analysis of a few individual videos cannot achieve as efficiently. Second, the montages palpably address the tensions created as MMP attempts to suture various working-class struggles within a more unified class narrative. As Bryan Mercer notes, there is a strategic difficulty in that MMP attempts to confront two related but different goals: "trying to knit people together around a number of issues or finding an issue that stands out as a universal issue for everyone." Members of MMP fully recognize this difficult, if not impossible task. Shivaani Selvaraj, a founding member of MMP, relates that the organization "is a constantly not complete project. A part of the tension is the gap between the imagination and reality. There is this imagination of the ideal and the reality of existent conditions" (Selvaraj 2010). So, in many ways, the MMP montages utilize the actually existing video-documented struggles of the year to hint at what a more substantive class alliance of the future might look like.

\section{MMP Montage Reels and Dinner}

The need for the end-of-the-year montage reels became apparent from the beginning of MMP's formation. Shivaani states, "We very deliberately understood that these people have never come together in the same room. We have a division of labor of different people supporting these coalitions. We were using media for that reason. Of course, we were going to make a montage. There is no other way to do it. After many years of organizing experience, you have to represent all the players. From the beginning, we very deliberately were about creating a new identity through this process. The work of montage is important for this new possibility of subjectivities" (Selvaraj 2010).

The December dinner gathers together all the coalitions involved with MMP to celebrate their work and screen the year-end montage reel. Ronald Blount recounts, "We get to sit down and see little clips of what we have done. It is inspiring to keep moving forward. It is like checking your blood pressure to keep moving forward, and the food is great" (Blount 2010). Similarly, Thomas Robinson observes, "We pledge to one another that 'I am here to support you.' It is the only way we can move forward. We can reflect on work that we did and the agenda on how to move forward and how to be better with what we are doing" (Robinson 2010).

Additionally, other interested affiliations are invited to the dinner. Ron enumerates, "We have little fun games, little ice-breakers to make them comfortable. We see the montage and go over a little bit of what we have done. A lot of people are curious to see what is going on" (Blount 2010). Thomas adds, "They come into the room and get talking with people and realize that I am going through the same thing as them. 'I would love to know how you guys went through that.' And you build those relationships, and it builds the network year after year and produces new leaders" (Robinson 2010).

Already it is apparent from MMP members' accounts that the montage reels serve as mobilizing tools for new members and catalysts for theorizing through future strategies by long-term members. This is an important reminder before going into the close-analysis of the montage reels that they serve multi-functional purposes that far exceed the ability of formal analysis alone. Yet, at the same time, formal analysis of the montage reels explores the types of visions made possible as the 
organizational and media practices of MMP change from year to year. So we must keep these two realms in mind-the functional and the formal—when discussing the videos.

When MMP began its video production, there was no formal process in place. Instead, the work was done informally with the staff possessing little to no training. Shivaani Selvaraj admits, "I was shooting and training other people with no film training experience" (Selvaraj 2010). She further recalls the tremendous difficulty in getting the early videos produced: "I remember the nightmare of coordinating that. I am sure that we lost so much footage over the years. There was no system for so long. Uggggh, I don't even know how we did it. We had different people volunteering. We were still relying on our personal connections with people who had the time and the desire to be able to shoot and edit. We had to rely on someone who often didn't have formal training themselves." Rebekah Scotland concurs, "Around the time I started [in 2007] there were only a few volunteers. Video production was about building a list and having people you can call on who may or may not help out" (Selvaraj 2010).

At this early stage of MMP's career simply getting the videos finished took precedence over producing high-quality productions. This was explicitly discussed among its volunteers. As Shivaani recalls, "I don't think we ever really had a desire to make sexy media. We weren't trying to make high-end produced pieces. A lot of the times, I am remembering we had a lot of conversations about this, about how our initial use of media was about internal coherence. What does it do for members of a group to see themselves on screen? Just getting the experiences of telling the story was a main part of the thing. That surpassed and continues to surpass a criticism of aesthetic value" (Selvaraj). The need to quickly get members involved in video production and the validation of their voices by projecting their stories on-screen remained priorities in order to develop the organizational capacity of MMP, as well as act in a timely manner for the various struggles like the unionization of security officers and maintaining the funding for Head Start. This is in accord with documentary theorist Jane Gaines' (1999) observation that "radical filmmakers have historically used mimesis not only in the interests of conscious change but also in the service of making activists more active-of making them more like the moving bodies on the screen." (Gaines 1999, 93) The main exception with MMP, however, is that the organizers are the moving bodies on the screen. The videos further build upon already engaged organizers to form wider coalitions and conceptualize their struggles in a more holistic and global manner.

The 2007 montage recounts in roughly ten minutes the coalitions and causes that MMP assisted throughout the year: the Philadelphia Student Union's fight against privatization of the Philadelphia public schools, the refunding of Head Start, the unionization of security officers and hotel workers, taxi workers protesting dangerous work conditions, and the fight against gentrification-to name only a few. The series of videos are mainly shot and edited in a minimalist manner: handheld camera, long shots, and talking heads. They relate an urgent need to simply document the stories and struggles of poor and working people. Moreover, they bring these different struggles into conversation so that cab drivers see the connection between their fight and the fight of Head Start parents or high schools students. The underlying belief is that through seeing the commonality of struggle a larger network of struggles would begin to develop across the region. As the videos progress, a somewhat more elaborate structure begins to emerge. For example, the Head Start video offers some tracking shots through a SEPTA train window of the stark industrialized landscape of inner-city Philadelphia while individuals recount in voice-over living in poverty.

But for the most part the videos mainly serve as a means of delivery of their message with minimal concern for form. These limits, however, should not be underestimated. Hand-held interviewbased filmmaking has often served a key place in establishing identification in bourgeois documentary filmmaking. Yet unlike bourgeois documentary filmmaking that often casts common people as victims when looking at social problems and places authority mainly with experts and the filmmakers, MMP empowers every-day people. According to Elizabeth Cowie, bourgeois social problem documentaries must present people as "properly helpless, as well as voiceless, or at least voicing only their plight, their suffering, and must not make any overt demands for help. Nor should they be able to provide a sophisticated analysis of their circumstances and its causes" (Cowie 1999, 32). MMP's members, however, are studying and learning together, actively protesting in the street, demanding equality and respect, while often offering succinct analysis of their situations. For example, one member of Head Start's parent council offers a quick but accurate history of community involvement with it: "We must know our history, and know that forty years ago before we were here that there were other people fighting and making sure that there was shared governance with parents and a parent policy council. So we must continue to fight for that for the next forty years and beyond. And it will be the parents who will determine if we have shared governance. We have a great number of people to say that, 'Listen, we want to talk to the legislators and let them know that 
Head Start works and that policy council works and that we continue to have this fight and we push for things because it is for the best of our children." So even within this rather simple form, the mere fact that MMP's members are crafting their own stories, shooting their own footage, and involved with editing counters commercial media's often disparaging view of the poor as helpless victims locked into a social context that they cannot even comprehend, let alone act against. The videos show them actively engaged in collective struggles, which are the natural results of their deliberation. Thought and action, as a result, become unified to reveal all the elements that comprise collective action.

Epitomizing the challenges of generating class forming Narrative Practices across the experiences of the isolated poor and working class constituencies, the 2007 montage largely fails to explain how these struggles are unified. At best, the montage brings the struggles physically within proximity of each other through editing, and the montage shows the struggle against forms of economic and political oppression as they are manifested across the city and region. As Rebekah Scotland observes, "You can't force something that can't be done on its own. We try to place these things together as best we can. But if the individual groups aren't doing it, then we can't do it. If they are fighting on individual fronts, then we can't make them identify with each other. The montage is our best to get at that unity that might not exist yet, even though they are fighting on a more narrow focus" (Scotland 2010).

Tellingly, the one moment of unity among coalitions occurs naturally at the end of the video when various groups like the Philadelphia Student Union, Jobs for Justice, hotel and healthcare workers, and taxi drivers join security officers in their fight against poor working conditions of Allied Barton. The theme of unity within the sequence is highlighted by the caption: "Building a Network," and is illustrative of what we call Shared Struggle in our concentric circle model. One activist from Jobs for Justice states: "We are here to show solidarity with the Allied Barton guards. Every service industry in the city: restaurant workers, hotel workers, the taxi drivers, all of us, we're being stepped on. And the only way that we're going to change that is if we all come together." While he speaks, we watch sequences of students and other groups marching in the street. The unity among workers is rather eloquently expressed through fluid camerawork and editing-as if form and content finally synch-up for the remaining minute-and-a-half of the video. The sequence provides a closing gesture of MMP's future ambitions to not only unify workers, but also produce more seamless video making.

By the time of the 2008 montage, MMP had grown to a network of eight organizations with between 50-100 members. Furthermore, with additional resources and a growing budget MMP was able to hire some full-time and part-time staff with more concrete media and video production skills. Along with the new staff MMP had also grown in prominence and this drew a more capable crowd of media-makers that wanted to volunteer within the MMP network. The combination of factors led the 2008 montage to have a more polished feel than the prior year's montage.

The 2008 montage frequently layers music with voice-overs, cuts in a more sophisticated and frequent manner, incorporates tripod shots with handheld footage, minimizes talking-heads with dynamic shots of coalitions organizing, speaking, and rallying, uses more professional quality video equipment that reduces the graininess that the prior year's montage exhibited, and adds Spanish subtitles. As a result, the montage is more dynamic. Much of the opening sequence takes place at an MMP leadership school held in the summer of 2008 at Villanova University outside of Philadelphia. During a three-day session over 100 leaders from the different groups within the MMP network converged to build relationships, study together and make a plan. The school played a central role in the 2008 montage.

Similar to the end of the 2007 montage, the video highlights the natural alliances among coalitions to suggest the emerging class alliance that MMP fosters. The video also ends with the collective spaces of rallies, conferences, and meetings to punctuate the frequency of these growing coalitions and an increasingly unified intra-working-class identity. As Rebekah notes, "The beginning and the end focus on these spaces and conversations where a lot of study has been going on. It closes on the leadership space in West Virginia where we speak together about a broader struggle. It is difficult to capture that because it is an internal conversation" (Scotland 2010). Although it might be difficult to capture that conversation, the editing of multiple voices intersecting with other images, once again, hints at a sense of fluidity, growth, and suturing of class subjectivity. The increase of images and voices of people speaking with one another from the 2007 montage to the 2008 one suggests the exponential strengthening of this new subjectivity.

Interestingly, the main section of the video organizes itself around media-specific projects that were produced through MMP Radio Network, Labor Justice Radio, and MMP video collaborations. As a result, the video explicitly evokes at its beginning and ending how media production assists in 
suturing this new class subjectivity. Furthermore, the central attention given to media suggests the ways in which formal concerns and media practices were going through re-evaluation by some MMP members. For example, Rebekah recounts how MMP at the time began thinking about how to institutionalize a more permanent video production unit that could meet specific deadlines and perhaps initiate investigative journalism.

This increased training and new expertise in filmmaking powerfully manifests itself in the video excerpt of A New Era in the 2008 montage. Rather than rushing right to its message, the excerpt emphasizes mood and context. It opens with a hand-held tracking shot of cabs lined up in Center City. It then cuts to cab drivers coming to Philadelphia's central Amtrak station, 30th Street Station, in order to vote for president of the Taxi Workers Alliance. Playing over these images is an allied musician singing a song written for the cab drivers campaign, with a drawl, "Listen up, ya'll taxi drivers, in Phil'delphia town. We're sick and tired of the man always keepin' us down." This opening establishes a very intimate and united space where music and images merge, and strength is implied in its more relaxed pacing. A voice-over in Haitian accent enters as we watch men continually vote. Quincy Tarylor, a cab driver and organizer at 30th Street Station then comes on the screen and says, "I believe that the organization of this type would be able to help us as cab drivers within the entire city." The images not only reinforce the voice-over's professed belief in a taxi driver union, but the sharing of the audio space between Haitian voice and the Southern white drawl of the singer also accents the racial diversity of the cab drivers who comprise the union. Within the matter of a minute, the film masterfully establishes the unity yet diversity and confidence through form, music, and content that the taxi worker's alliance provides.

With the creation of the 2009 montage, MMP had established a much more permanent and institutionalized video production unit. With an even larger budget and more staff coming onto permanent positions MMP was better able to manage the media-production workflow, transferring productions mainly to digital copies rather than relying on tapes. As Bryan Mercer explains, "Working with tapes is a problematic part of the workflow" since they are difficult to store, can easily get lost, and often requiring transferring to a more media-accessible form (Mercer 2010). He continues, "For 2009, we had all the media accessible to us so that we could digitally pull back new content whenever it was needed." Yet, he added, that two other major components further enhanced video production quality: "We have an increased range of people working on the media. We have gone from just scattered filmmakers and people just getting trained on video to now having consistent teams making the videos. The other piece is we have figured out how to do low-end video work, as well as the high-end work, too," which allowed the organization to differentiate between levels of experience that didn't place video production at cross-purposes. What needs emphasis is that while MMP grew and was able to hire permanent staff and video units, it nonetheless maintained and intensified its original mission of self-empowerment and self-representation. It promoted the leadership development of its constituency and resisted establishing a more "professionalized" organizational structure that disconnected media-making from the people being represented for the sake of higher-quality, better produced products.

One of the major transformations of 2009 was finally making MMPTV operational. Much of the initial inspiration of MMPTV was modelled after the successful Labor Justice Radio, which launched in 2008 and is comprised of seven workers and allies who come together weekly to make and produce a radio show for MMP that is aired on a low power FM station in West Philadelphia. Bryan comments: "Part of the lesson for the t.v. show was the lessons out of our radio show, Labor Justice Radio. It is organized around a team of people-some of whom are union members, some are low-wage un-unionized workers, and others who just care about labor issues. They come together monthly to decide what should be done for a show. They then go out and record and then produce the show. It has produced some of our best and most clear people. They have a clear space to come together. We want to achieve the same lessons through the video format" (Mercer 2010). Rebekah further explains, "I want MMPTV to be based on a structure that is flexible. Hopefully a lot of people in that crew would remain a part of it. The way it is going to work is by having clearly identifiable roles: someone being a reporter for this segment this month then perhaps being an interviewer the next. We can also incorporate someone who wants to be a part of the production but only has an hour for that month that he/she can do it. MMPTV can encapsulate the filmmaking side now. It is something at the beginning of the month that we can arrange what our plan is. And we can have more regularly involved people who can take up the new work" (Scotland 2010). The videos produced through MMPTV are not just used by coalition partners, but also assembled into a half-hour show that is broadcast both on the MMP website <http://mediamobilizing.org/> and over the public access stations, Phillycam, twice a week with the show repeating for a month or two. 
The 2009 montage reveals traces of these changes in that it is the most ambitious of the three montage reels. Not only has the editing, framing, and technical quality improved, but the montage possesses a culture jamming attitude by appropriating commercial news broadcasts, archival historical footage of Martin Luther King, Jr., and music by Radiohead and TV on the Radio for its own politicized purposes. This incorporation of culture jamming adds a new, interesting dimension to the montage: rather than simply highlighting the oppositional role of independent media and social movements, the video suggests a more complicated relation between the work of MMP and surrounding commercial culture. Like much culture jamming, it employs the Situationist notion of détournement: "a turning around and reclamation of lost meaning: a way of putting the stasis of the [commercial] spectacle in motion [...] and reveal[s] a totality of possible social and discursive relations which exceeds the spectacle's constraints." (Benning 1992, 86-88)

Similar to how the Situationists reclaimed comics and films to re-inflect them along lines of working-class struggle, MMP hijacks commercial news broadcasts of the 2008 economic collapse to MMP's mission of establishing a working-class subjectivity. For example, in the video's opening sequence, one newscaster announces: "While the DOW climbed higher again today helped along by more solid bank earnings, we learn that Americans continue to lose their homes to foreclosure at the rate of 425 every hour, seven every minute." The sequence already reveals how even commercial media cannot hide the inversely proportional relationship between the economic health of investors and that of everyday people. The DOW's health remains untethered from the rampant poverty that engulfs working people and confiscates their homes.

But this narrative of economic collapse, desperation, and victimization thundering across commercial news outlets is integrated into a more empowering framework of the voices of workingclass people in their class fight against dispossession. In one instance, over images of workingclass people marching with signs stating, "We Stand with the Workers," we hear the voice-over of Amendu Evans, an MMP media-maker and leader, janitor, and shop steward for SEIU Local 32BJ say: "People have been thrust into poverty who had never been in poverty before but now see that they will be able to align to the people who had always been in poverty. Then maybe we can come together and see that all our goals will be benefited by us working together." The economic collapse, according to MMP's scenario, can also be viewed as an opportunity to not only suture an intra-working-class subjectivity, but also an inter-class subjectivity that unites the recently fallen from the white collar world with the goals of blue-collar, service-industry workers who have been forced to think about and organize against neo-liberalism's downside since the beginning. The image of people marching suggests how mobilization is already occurring that the white collar might be able to access. The overall sequence reveals the complex relation between independent and commercial media. It does not simply denounce commercial media of lying but instead reveals its constrained presentation of the issue in a disempowered framework. MMP's goal is to harness this half-truth into a more engaged and broader outlook.

Unfortunately, this framework is dropped after two minutes only to be supplanted by another meta-narrative concerning the unifying ability of independent media. As one unnamed voice-over states: "We see media and communications as the central nervous system of a movement against poverty led by the poor. Our radio, Internet, video, and study led together the struggle of working people in Philadelphia and beyond creating our tapestry of our resistance." Footage follows of the various fights. Not unlike the 2008 montage reel, the video is split in half with the introduction and conclusion emphasizing movement-building and the middle section focusing on media. But the links between media and movements are never made entirely clear. How media is supposed to suture these coalitions into an intra-working-class subjectivity or its links with an overarching frame of economic collapse remains under-developed.

In some ways, the 2009 montage is more awkward than the 2008 due to its ambition to employ new formal techniques found in commercial documentaries such as voice-of-god narration. Throughout the montage, various disembodied voices speak in the royal "we" for the Media Mobilizing Project and jeopardizes to over-power the other embodied voices. The narrative feels more forced, awkward, and hierarchical with those of authority speaking for people rather than letting them chose their own words. For example, we hear an unidentified woman state in voice-over: "Our work for Federal reform must be grounded in supporting local struggles to protect and improve the institutions that serve poor and working-class people in Philadelphia." As she speaks, we see people protesting. This is followed by a health care worker speaking on her front porch about hospital closures in an effort to create a balance between omniscient narrator and visible subjects. But this doesn't alleviate the discrepancy between those unidentified, disembodied voices that can speak in a more universal manner and those of specific working-class people who are identified and speak mainly in regards to their own struggles. Although this disconnect between omniscient narrators 
and working-class voices speaking about particular struggles is partially mitigated by the December dinner screening since most of the viewers connect the narrators with specific people who they know, it still doesn't solve the formal hierarchy of those who can speak frequently in a universal manner from those who cannot nor does it mend the diversity of struggles into a convincing unified working-class subjectivity.

If anything, the sequence highlights the tensions between MMP's desire to equitably represent singular struggles, while at the same time, as MMP leadership explains, illustrate how these singular narratives come together to form the larger narrative of the class. ${ }^{2}$ It also reveals how the incorporation of certain mainstream techniques from commercial documentaries like voice-of-god narration in an attempt to suture these struggles together actually exacerbates the problem on a formal level. Yet, on a practical level, in terms of the actual screening location with most viewers being able to identify most, if not all, of the disembodied narrators since they have intimately worked together, the voice-of-god technique might not seem so alienating and authoritative. This sequence, ultimately, highlights the need to draw attention to the multifarious ways in which we must approach socially engaged media that can hold vastly different formal and site-specific meanings.

MMP, however, is well aware of these problems. In regards to the voice-over, Bryan states, "It is an experiment. If we have an opportunity to create a link, then we go for it. But it is by no means perfect" (Mercer 2010). Rebekah adds, "We made the video a week before the dinner. We wanted to incorporate more voices, but we didn't have the time. It's hard to find all the voices to all the footage and weave a story." Furthermore, she believes the lack of unity in the 2009 montage harkens to an even more significant issue: "There is this way of trouble capturing what is MMP. In the last video we tried to put across what MMP is trying to do, but it still doesn't speak about what MMP specifically does. It is rather ubiquitous but not visible yet" (Scotland 2010). But these limits lead the organization to constantly experiment with new forms, which at times might hinder rather than assist establishing a unified vision as the aforementioned example regarding voice-of-god narration suggests. Many members hold a similar view to Ronald Blount when he states, "I just think MMP hasn't really arrived at where it will truly be at. It is still evolving. It is half-way where it is going to be. It is amazing the way it has matured in the last four or five year" (Blount 2010).

As the end-of-the-year montages reveal, the transformations regarding video production within MMP have been significant. Along these lines there are a few lessons we can draw from the video production process as well as media texts themselves as tools for building working class-identity. The first lesson is that media, and in this case video, is a key tool for creating a socialized suturing that works to cultivate new class-based subjectivities across a variegated community. That said, the process of cultivating a new class based-subjectivity is difficult and the problems are not simply resolved by the increased institutionalization of video production within MMP. In this sense, it becomes clear that higher quality video production that incorporates commercial techniques creates its own problems in cultivating a unified class identity as the problems with voiceovers illustrates. Finally, the video production process and the media texts show that producing new class based subjectivities seems to work most fluidly when the varied parts of the class are working together on a class project or what we call shared struggle. In this sense, the videotexts follow-real world offline projects where communities and subjectivities are already forming. At its best, the media can translate this already forming subjectivity and represent it to the community in a feedback loop.

\section{Conclusion}

This article examined the role that media and communication play for contemporary social movements and social movement based identity and group formations. Contrary to others who point to the primacy of collective identities around such signifiers as gender or race, we argued for bringing back in the pivotal structural dimension of class around which collective selves form.

On the basis of an understanding of class as involving a process of self-making, we redeployed and modified core elements of suture theory, stressing a more materially grounded and collective approach. This allowed us to analyze how social movements in general and MMP in particular employ media such as video production to collectively suture the fragmented groups of workers into a class formation that begins to resist and challenge the hegemony of neoliberal capitalism.

Moreover, we drew on the model of Concentric Practices, which conceptualizes the role of media and communications in contemporary class formations along the overlapping circles of communicative spaces, narrative practices and shares struggles. More specifically, in this article we em-

\footnotetext{
${ }^{2}$ The belief amongst MMP leaders that each of the singular struggles are connected and part of a larger story of the class is something which is repeated in interviews and illustrated in much of the language MMP uses to define the mission of the organization.
} 
phasized the narrative practices dimension, illustrating and analyzing the way in which the Philadelphia-based Media Mobilizing Project uses media in general and its video reels in particular to foster class alliances. We pointed to the role of conceptualizing stories, which in turn lead to crossidentifications between workers or/and across workers and high school students.

These processes of suturing new class-based identities through media emphasize the increasing importance of media and communication. Due to the increasingly atomized, isolated nature of social life, as well as the apparent splintering of the working class under neoliberal capitalism, media serve a pivotal infrastructural function for generating the necessary commonality between the fractured sectors of the contemporary working class. Moreover, our analysis shows the necessity to present and think about media in general and MMP's videos in particular not as an endpoint unto themselves, but instead as catalysts for further organization building and the renewed suturing of class alliances. These further suturing processes can be analyzed in, for instance, shared struggles, the third dimension of the Concentric Practices model and the task of future research. Finally, our analysis goes against the simplistic and often disparaging view of the poor as helpless victims. This article indicated their engaged and collective struggles and their use of media foster a classbased identity. However, the thick textual analysis also brought out the tensions and challenges that emerge as MMP seeks to suture various working class struggles into a more coherent and unified class-based social movement for the city of Philadelphia. Although media-making is not a panacea for the alienation visited upon working-class people by neoliberal practices, it provides a central function by harnessing and furthering collective tactics and strategies that assist in developing class consciousness and an empowered sense of identity.

\section{References}

Atton, Chris. 2002. Alternative Media. London: Sage.

Benning, Sadie. 1992. The Most Radical Gesture: The Situationist International in a Postmodern Age. New York: Routledge. Berger, Dan, Peter Funke, and Todd Wolfson. 2011. Communications Networks, Movements and the Neoliberal City: The Media Mobilizing Project in Philadelphia. Transforming Anthropology 19 (2): 187-201.

Blount, Ron. 2010. Interview with Chris Robé on December 10, 2010. [Phone interview].

Couldry, Nick. 2003. Beyond the Hall of Mirrors? Some Theoretical Reflections on the Global Contestation of Media Power. In Contesting Media Power: Alternative Media in a Networked World, edited by Nick Couldry and James Curran, 39-54. New York: Rowman and Littlefield.

Cowie, Elizabeth. 1999. The Spectacle of Actuality. In Collecting Visible Evidence, edited by Jane M. Gaines and Michael Renov, 19-45. Minneapolis: University of Minnesota Press.

Downing, John. 2001. Radical Media: Rebellious Communication and Social Movements. London: Sage Publications.

Fuchs, Christian. 2010. Labor in Informational Capitalism and on the Internet. The Information Society 26 (3): 179-196.

Funke, Peter, and Todd Wolfson. Forthcoming. Communications and Class Identity: Developing a Contemporary Rubric. In Social Identity and Media: New Agendas in Communication Research, edited by Dominic Lasorsa and America Rodriguez. New York: Routledge.

Gaines, Jane M. 1999. Political Mimesis. In Collecting Visible Evidence, edited by Jane M. Gaines and Michael Renov, 84102. Minneapolis: University of Minnesota Press.

Ginsberg, Faye. 2008. Rethinking the Digital Divide. In Global Indigenous Media: Cultures, Poetics, and Politics, edited by Pamela Wilson and Michelle Steward, 287-305. Durham: Duke University Press.

Goffe, Rachel, and Todd Wolfson. 2012. Annihilation of Space by Media: Making Connections through a Fragmented Neoliberal Landscape. In Fight to Stay Put: Social Lessons through Media Imaginings of Gentrification, Displacement and Resistance, edited by James Craine, Giorgio Curti and Stuart Aitken. Stuttgart: Franz Steiner Verlag, in press.

Goode, Judith, and Jeff Maskovsky. 2002. New Poverty Studies: The Ethnography of Power, Politics and Impoverished People in the United States. New York: NYU Press

Hardt, Michael, and Antonio Negri. 2004. Multitude: War and Democracy in the Age of Empire. New York: Penguin

Harvey, David. 1990. The Condition of Postmodernity: An Enquiry into the Origins of Cultural Change. Cambridge: Blackwell.

Harvey, David. 2005. A Brief History of Neoliberalism. New York: Oxford University Press.

Heath, Stephen. 1981. Questions of Cinema. Bloomington: Indiana University Press.

James, David E. 1996. Power Misses: Essays Across (Un)Popular Culture. New York: Verso.

Liu, Alan. 2004. The Laws of Cool: Knowledge Work and the Culture of Information. Chicago: University of Chicago Press.

Lukacs, George. 1972. History and Class Consciousness. Boston: MIT Press.

Marx, Karl. 1992/1847. The Poverty of Philosophy. New York: International Publishers.

Mercer, Bryan. 2010. Interview with Chris Robé on November 18, 2010. [Phone interview].

MMP. 2010. Media Mobilizing Project. Accessed August 12, 2011. http://mediamobilizingproject.org

Negri, Antonio. 1989. The Politics of Subversion: A Manifesto for the Twenty-First Century. Cambridge: Polity.

Renov, Michael. 2004. The Subject of Documentary. Minneapolis: University of Minnesota Press.

Robinson, Thomas. 2010. Interview with Chris Robé on December 13, 2010. [Phone interview].

Rodriguez, Clemencia. 2001. Fissures in the Mediascape: An International Study of Citizens' Media. New Jersey: Hampton Press.

Scotland, Rebekah. 2010. Interview with Chris Robé on November 5, 2010. [Phone interview] 
Sites, William. 2007. Contesting the Neoliberal City: Theories of Neoliberalism and Urban Strategies of Contention. In Contesting Neoliberalism: Urban Frontiers, edited by Helga Leitner, Jamie Peck and Eric Shepperd, 116-138. New York: The Guilford Press.

Thompson, E. P. 1966. The Making of the English Working Class. New York: Vintage.

Tronti, Mario. 1973. Social Capital. Telos 17: 98-121.

\section{About the Authors}

Peter Nikolaus Funke

is Assistant Professor in the Department of Government and International Affairs at the University of South Florida in Tampa. Peter received his Ph.D. from the University of Pennsylvania and his Vordiplom from the Freie Universität Berlin. His research focuses on social movements, new media, and class formation under globalizing capitalism and has been published in journals such as Globalizations, International Critical Thought, New Political Science and Transforming Anthropology. Peter's work has been supported by the Social Science Research Council. Currently he is working on a book length study on the World Social Forum and the Rhizomatic Left.

Chris Robé

is an Associate Professor of Film and Media Studies at Florida Atlantic University. University of Texas Press published his monograph, Left of Hollywood: Cinema, Modernism, and the Emergence of U.S. Left Film Culture in 2010. He has published articles regarding radical film and media movements in various journals like Cinema Journal, Framework, and Jump Cut. He is a frequent contributor to Pop Matters <www.popmatters.com>.

Todd Wolfson

is an Assistant Professor in the Department of Journalism and Media Studies at Rutgers University. His research focuses on the convergence of new media and social movements. Todd is also a co-founder of the Media Mobilizing Project, which uses media and communications as a core strategy for building a movement to end poverty led by poor and working people in Philadelphia and across the region. 